\title{
Clinical impact of delays in the management of lung cancer patients in the last decade: systematic review
}

\author{
María Guirado ${ }^{1}$ • Elena Fernández Martín ${ }^{2}$. Alberto Fernández Villar ${ }^{3} \cdot$ Arturo Navarro Martín $^{4}$. \\ Alfredo Sánchez-Hernández ${ }^{5}$
}

Received: 2 December 2021 / Accepted: 24 December 2021 / Published online: 7 March 2022

(c) The Author(s) 2022

\begin{abstract}
Introduction Due to the importance of lung cancer early treatment because of its severity and extent worldwide a systematic literature review was conducted about the impact of delays in waiting times on the disease prognosis.

Materials and Methods We conducted a systematic search of observational studies (2010-2020) including adult patients diagnosed with lung cancer and reporting healthcare timelines and their clinical consequences.

Results We included 38 articles containing data on waiting times and prognosis; only 31 articles linked this forecast to a specific waiting time. We identified 41 healthcare time intervals and found medians of 6-121 days from diagnosis to treatment and 4-19.5 days from primary care to specialist visit: $37.5 \%$ of the intervals indicated better prognosis with longer waiting times. Conclusions All articles emphasized that waiting times must be reduced to achieve good management and prognosis of lung cancer. Further prospective studies are needed on the relationship between waiting times and prognosis of lung cancer.
\end{abstract}

Keywords Lung cancer $\cdot$ Timeliness of care $\cdot$ Delays $\cdot$ Prognosis $\cdot$ Survival $\cdot$ Systematic literature review

María Guirado

mariaspalux@hotmail.com

Elena Fernández Martín

efernandezmartin@salud.madrid.org

Alberto Fernández Villar

Jose.Alberto.Fernandez.Villar@sergas.es

Arturo Navarro Martín

anavarro@iconcologia.net

Alfredo Sánchez-Hernández

asanchezh@seom.org

1 Medical Oncology Department, Hospital General Universitario de Elche, 03203 Elche, Spain

2 Thoracic Surgery Department, Hospital Clinico San Carlos, Madrid, Spain

3 Pneumology Department, Hospital Álvaro Cunqueiro de Vigo, Instituto de Investigación Sanitaria de Vigo, Vigo, Spain

4 Radiation Oncology Department, Hospital Durani Reynals, Hospitalet, L'Hospitalet de Llobregat, Barcelona, Spain

5 Medical Oncology Department, Consorcio Hospitalario Provincial de Castellón, 12002 Castellon, Spain

\section{Introduction}

Lung cancer, the leading cause of cancer death worldwide, is a health problem of the first order due to the morbidity and mortality caused, and the economic impact it has on health systems [1,2].

Diagnostic suspicion of early-stage lung cancer may be difficult because the clinical presentation is silent in the early stages and the differential diagnosis may be confusing in advanced stages. Progressive improvements in local and remote diagnostic techniques (EBUS and PET-TAC) and therapeutic advances (targeted therapies, immunotherapies, etc.) in the last decade have improved the prognosis in patients with lung cancer in advanced countries, including Spain. Five-year survival is between 12 and 18\% [3] and is directly related to the stage at presentation and the histology: the 5-year survival of patients with localized stages of the disease ranges between $27 \%$ and $63 \%$, in regional stages between 16 and $35 \%$ and in disseminated stages between 3 and $7 \%$, with the lowest survival rate corresponding to small cell lung cancer (SCLC) [4]. In 2020, 1,796,144 deaths worldwide and 22,930 deaths in Spain were due to lung cancer $[3,5]$. 
The clinical management of lung cancer patients requires complex coordination by specialized medical and surgical services, health service administrators, care managers and social service providers. The traditional approach of referring patients to different specialist consultations sequentially often results in care that is perceived as slow, fragmented, and poorly coordinated. To reduce these delays, agreed standards have been established for maximum acceptable waiting times for lung cancer-specific referral, diagnosis, and treatment times based on expert clinical opinion $[1,6$, 7].

In the United Kingdom, the National Optimal Lung Cancer Pathway guidelines propose care algorithms to be used in conjunction with the British Thoracic Society (BTS) and the National Institute for Health and Care Excellence (NICE) guidelines, with the aim of achieving maximum times of 14 days for diagnosis and 28 days for treatment. However, these standards are not always met and delays in lung cancer care persist [1].

It is essential to obtain optimal clinical results in patients with suspected lung cancer to speed up the diagnostic process and early treatment as much as possible. Delays in any part of the process, from the initial evaluation and referral to the definitive diagnosis, treatment and follow-up may have negative consequences $[1,6,8,9]$.

Considering the importance of an early approach in the diagnosis and treatment of lung cancer, we carried out a systematic literature review (SLR) to determine the evidence of the impact of delays in the times of diagnosis and initial treatment on the disease prognosis.

\section{Materials and methods}

The SLR was carried out according to the Preferred Reporting Items for Systematic Reviews and Meta-analyses Statement (PRISMA).

We selected observational studies of patients aged $\geq 18$ years diagnosed with or with a clinical suspicion of small cell or non-small cell lung cancer conducted in Europe, the United States, Canada, Japan, Australia, New Zealand, and China. The study had to evaluate $\geq 1$ variable related to healthcare deadlines and their effect on clinical outcomes. Randomized clinical trials were not included.

Two search strategies were designed, one for MEDLINE (through PubMed) and one for EMBASE, in which terms related to lung cancer, healthcare deadlines (waiting times, delays, early diagnosis, etc.) and clinical outcomes (prognosis, survival, mortality, etc.) were used. The time horizon of the search was January 1, 2010-November 24, 2020, to include advances in the last decade in the diagnosis and treatment of lung cancer. The language of the publications was limited to English and Spanish.
The titles and abstracts resulting from the search, after duplicate articles were removed, were evaluated by three reviewers (AGC, IAF, and MCA), and those that did not meet the inclusion and exclusion criteria were ruled out, noting the specific reasons. If there was disagreement between reviewers regarding the inclusion of an article, the criterion of a fourth reviewer (FIO) was used. A complete reading of the articles was made by three reviewers (AGC, IAF, and $\mathrm{MCA}$ ) independently, and the reasons for non-selection were recorded.

Data from the selected articles were tabulated by three reviewers (AGC, IAF, and MCA) on a form developed specifically for extraction and validated by a fourth reviewer. From each article selected, we extracted the study characteristics (type of study, design, country of study, sample size, study duration, follow-up time), patient characteristics (mean age, sex ratio, disease stage), healthcare deadlines (time intervals evaluated between symptoms, diagnosis, and treatment [including mean, standard deviation, median or interquartile range]) and clinical outcomes (survival, mortality). All waiting time intervals were analyzed in calendar days (if an article reported delays in weeks, these values were multiplied by 7 ; if it reported delays in months, they were multiplied by 30.41 ).

All results focused on the healthcare timelines of lung cancer patients and their clinical consequences were evaluated.

The times evaluated were expressed as: (a) time from the appearance of symptoms or clinical or radiological suspicion (first abnormal imaging test) to the therapeutic intervention, (b) partial times, considering: (b1) time from the appearance of symptoms, clinical or radiological suspicion to diagnosis (lung cancer study, staging), (b2) time from diagnosis to therapeutic decision, (b3) time from therapeutic decision to treatment initiation. Clinical outcomes related to the prognosis were progression-free survival, overall survival, time to relapse, and mortality.

Initially, given the variations in the times considered and to interpret the information in the most aggregated and homogeneous way possible, the time intervals were grouped sequentially following the timeline that goes from diagnosis to treatment. The groups of time intervals evaluated were described using absolute frequencies $(n)$ and percentages with respect to the total number of articles selected.

To evaluate the relationship between the time intervals stated and their association with the prognosis, we made a qualitative analysis that categorized the possible relationship between the time intervals and the specific prognosis in relation to survival and mortality. 


\section{Results}

The search strategy and the decisions made during the selection of the articles included in the SLR are shown in the PRISMA flowchart (Fig. 1). The search identified 1359 articles for review, of which, after eliminating duplicate articles, 1146 were assessed for eligibility based on the title and abstract; of these, 1027 were excluded, mostly because they did not provide variables related to waiting times. The full text of the remaining 119 articles was evaluated, and 81 were excluded, mainly because they did not include variables related to the disease prognosis $(n=52)$ or waiting times $(n=16)$. Finally, 38 met the inclusion criteria.

\section{Description of the studies}

Thirty-four studies were retrospective observational studies, three were prospective observational studies, and one was a systematic literature review.

The studies included 1,225,328 patients, with a sample size ranging from 128 to 691,464 . Twenty-one studies were conducted specifically in patients with non-small cell lung cancer (NSCLC), 13 in patients with any type of lung cancer, 3 in patients with SCLC, and one in patients with epidermoid NSCLC. Twenty-one studies investigated all disease stages, four included only patients with stage I-III, three included stage III and IV patients, three studies only included stage I patients, two studies included stage I and II patients, one study only included stage III patients, and another included only stage II and III, three studies did not specify this information.

There were wide variations and heterogeneity among the studies included. The quality was evaluated using the National Heart, Lung and Blood Institute tool. One of the most common shortcomings was the lack of justification of the number of patients needed to detect a relationship between the waiting time and the prognosis, and the statistical adjustment of the variables influencing the prognosis.

The characteristics of the studies selected are shown in Table 2.

\section{Description of times}

In the 38 selected articles, the results of 41 healthcare time intervals were originally described, which conditioned the type of analysis. The most common waiting times were from symptoms to treatment ( 7 articles, $19 \%$ ), symptoms to diagnosis (7 articles, 19\%), first specialist visit to diagnosis (7 articles, $19 \%$ ), specialist referral to surgery or treatment (8 articles, 22\%) and from diagnosis to treatment (19 articles, $51 \%$ ) (Fig. 2). The median of the times studied was two

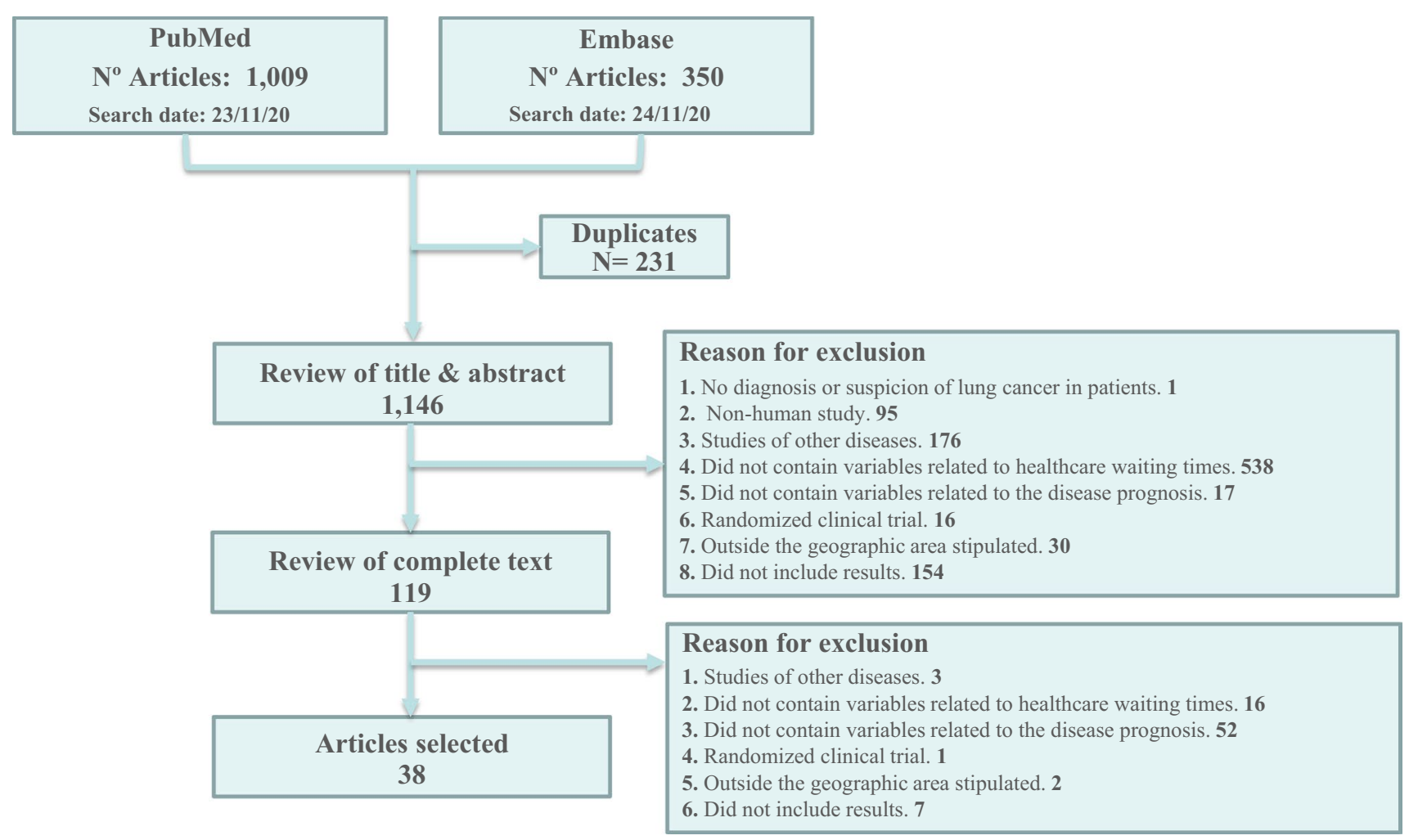

Fig. 1 PRISMA flowchart 


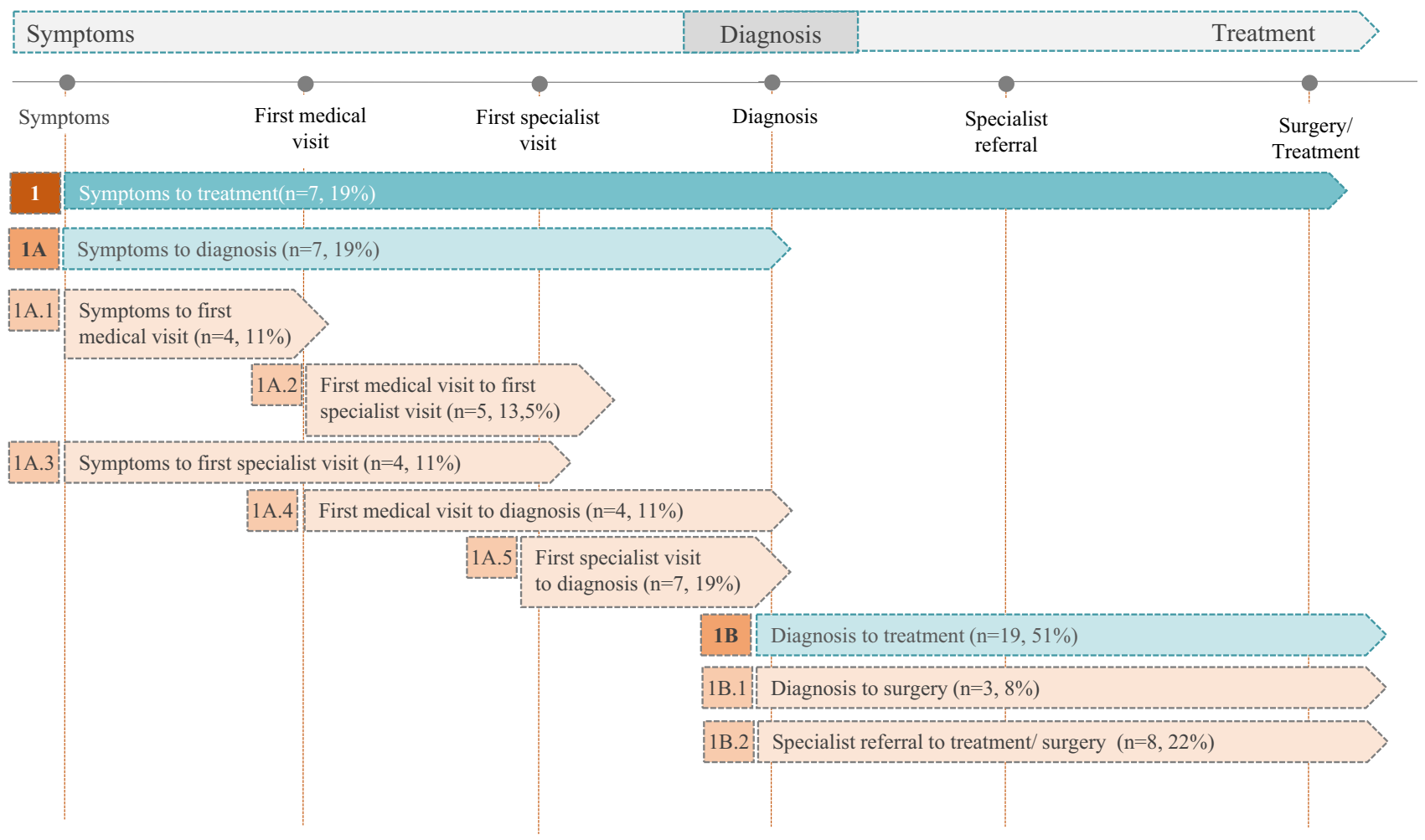

Fig. 2 Time intervals according to the specifications of the articles selected

time periods in the same study (IQR 1-4), with a maximum of 10 . There were wide variations in how the results of the healthcare deadlines were summarized statistically including means, medians, minimum-maximums, and percentage of patients with delays in the time interval studied.

\section{Description of healthcare time intervals}

In articles that studied the time from symptoms to treatment in patients with lung cancer stages I-IV, the median (range) waiting time was 87.5 days (44-130.5). In patients with SCLC stages I-IV, one study reported the median waiting time was 78 days. In patients with NSCLC stages I-IV, the mean was 138.5 days and in patients without a definite stage the median was 62 days. Kuroda et al. [10] defined delay as a wait of $>6$ months after diagnosis and until surgical treatment and found that, in patients with NSCLC stage IA, the mean waiting time was 411 days in patients treated in $<2$ years, compared with 1669.9 days in patients whose waiting time was $>2$ years.
Studies that directly assessed the time from symptoms to diagnosis reported mean or median waiting times of $>20$ days. In patients with lung cancer stages I-IV, the median (range) waiting time was 33 days (23-66), and in patients with lung cancer where the stage was not specified, the median was 56 days. The median time was 69 days in patients with SCLC stages I-IV, and 75 days in patients with NSCLC. Concannon et al. [11] distinguished between patients with NSCLC stages I-II who were homeless (mean waiting time of 248 days) and those who had a home (mean waiting time of 116 days), and patients with NSCLC stages III-IV who were homeless (mean waiting time of 34.7 days) and those who had a home (mean waiting time of 46 days).

Several studies evaluated the means and medians of specific waiting times for different subintervals within the symptoms to diagnosis time, specifically:

- For the symptoms to first specialist visit time, the median (range) waiting time was 33.25 days (8-53) for patients 
with lung cancer stages I-IV, and the mean of the means was 53.33 days.

- For the symptoms to first medical visit time, the mean of the means of waiting time for patients with lung cancer without stage specification was 44.52 days, and for patients with lung cancer stages I-IV, one study reported a median of 58 days. For patients with SCLC stages I$\mathrm{IV}$, the median reported by one study was 30 days and a mean of 56.7 days in patients with stages I-IV NSCLC was found by another study.

- For the first medical visit to first specialist visit, the median of the medians of waiting time for patients with lung cancer stages I-IV was 5 days. One study reported a mean of 14.49 days in lung cancer patients without specifying the stage. For patients with SCLC and stages I-IV NSCLC, the median was 19.5 and 17 days, respectively.

- For the first medical visit to diagnosis, the mean waiting time for lung cancer patients in whom the stage was not specified was 29.54 days in the study by Zicovic et al. [12] and a median of 88 days in the study by Redaniel et al. [13]. In patients with SCLC and stages I-IV NSCLC, the median was 34 and 40 days, respectively.

- For the first specialist visit to diagnosis, the median of the medians of waiting time in patients with lung cancer stages I-IV was 19.5 days, and the mean was 16.59 days in patients in whom the stage was not specified. In patients with SCLC stages I-IV, the median was 21 days and in patients with NSCLC stages I-IV the mean was 51.3 days.

For the diagnosis to treatment, the median of the medians of waiting time for patients with lung cancer stages I-IV was 31 days, and for patients in stage I-IIIA the mean was 35 days. Forrest et al. [14] indicated that $39.5 \%$ of patients had a delay in this time (defining delay as $>31$ days from diagnosis to treatment). They also evaluated the time from referral to the specialist until treatment (defining delay as $>14$ days) and found that $69.3 \%$ of patients had a delay. Samson et al. [15], defined a wait $\geq 8$ weeks as a delay of treatment, and studied patients diagnosed with NSCLC stage I, finding that the median time of patients who waited less than 8 weeks from diagnosis to treatment was 29 days, and that of patients who waited 8 weeks or more was 77 days. In patients with NSCLC stage III, Rice et al. [16] distinguished between patients with private insurance, those with basic coverage and those without insurance. The mean waiting times were 25, 48 and 52 days, respectively, and a waiting time $>30$ days was considered a delay. In patients with NSCLC stages I-II, the median of the medians of waiting time was 36.55 days. In patients with NSCLC stages I-III, the median wait between diagnosis and treatment was 28 days. In patients with NSCLC stages I-IIIB and IIIB-IV, the median was 121.6 days and 21 days, respectively. In patients with NSCLC stages I-IV, the median of medians was 33.5 days, in agreement with the study by Concannon et al. [11] in patients with NSCLC stages I-II who were homeless, in whom a median waiting time of 20 days and of 50 days in those with homes was reported. In patients with NSCLC stages III-IV without a home the mean was 49.9 days compared with 58.1 days in those with a home. Anggondowati et al. [17] distinguished according to disease progression, reporting median waiting times of 18 days for patients with metastases, 28 days for patients in the early stages and 27 days for patients in locally advanced stages. In patients with stages I-IV SCLC, the median of the medians of diagnosis to treatment was 7.5 days, while Bhandari et al. [18] found a mean of 18 days in these patients.

Three time periods that could not be grouped into any of the previously defined groups were identified: from the decision on surgery to the time of surgery, from diagnosis to contact with the specialist and from surgery to adjuvant treatment. The results were:

- For the decision on surgery to surgery, the percentage of patients with stages I to II NSCLC whose waiting time was $<1$ month was $24.8 \%$, between 1 and 2 months $44.1 \%$, between 2 and 3 months $19 \%$ and between 3 and 4 months $11.7 \%$.

- For the diagnosis to contact with the specialist, the median of medians in patients with lung cancer stages I-IV was 9 days, while Kanarek et al. [19] found the mean for NSCLC stages I-II patients was 61.2 days: in this study the surgeon was the specialist physician, after diagnosis by the oncologist.

- For the surgery to systemic treatment or vice versa, the median waiting time in patients with NSCLC stages I-III was 48 days, and in patients with stages I-IV 56 days. Odell et al. [20] defined delay as $>120$ days from chemotherapy to surgery and 180 days from surgery to chemotherapy: the percentage of patients with NSCLC stages I-IV with a delay, was $4 \%$ and $64 \%$, respectively. 
Table 1 Association between waiting times and survival

\begin{tabular}{llll}
\hline Time intervals & $\begin{array}{l}\text { Number of } \\
\text { articles }\end{array}$ & Association & References \\
\hline Symptoms to treatment & 2 & No association between delay and prognosis & {$[21,22]$} \\
& 3 & Longer waiting times improve the results forecast & {$[10,23,24]$} \\
Symptoms to first specialist visit & 2 & No association between delay and prognosis & {$[23,25]$} \\
Symptoms at first medical visit & 1 & Shorter waiting times improve the results forecast & {$[26]$} \\
& 2 & No association between delay and prognosis & {$[21,22]$} \\
Symptoms to diagnosis & 1 & Longer waiting times improve the results forecast & {$[12]$} \\
& 1 & Longer waiting times improve the results forecast & {$[21]$} \\
First medical visit to diagnosis & 2 & No association between delay and prognosis & {$[11,27]$} \\
& 1 & Longer waiting times improve the results forecast & {$[13]$} \\
First specialist visit to diagnosis & 3 & Shorter waiting times improve the results forecast & {$[12]$} \\
Diagnosis to treatment & 3 & No association between delay and prognosis & {$[12,25,28]$} \\
& 9 & No association between delay and prognosis & {$[11,28,29]$}
\end{tabular}

\section{Relationship between healthcare waiting times and the prognosis}

The 38 articles included reported, in addition to waiting times, the results related to the prognosis and 31 related the prognosis to a specific healthcare time evaluated. In general, there were wide variations in the results observed with respect to the prognosis in relation to the type of lung cancer studied, the stage and the time interval evaluated (Tables 1 , $3)$.

For the symptoms to treatment time, two studies reported no association between waiting time and survival or mortality, although Alanen [21] found improved survival when the waiting time was shorter in stage I patients. Three studies reported better patient survival when the waiting time was longer, although they justified these results by indicating that, in patients in earlier stages of the disease, the diagnostic study and assessment of staging may be more complex and require more tests, which could extend the times, compared with patients whose disease is more advanced.

For the symptoms to diagnosis time, two studies found no association with survival or mortality and one study reported improved survival when the waiting time was longer, associating this outcome with patients whose only possible treatment is palliative, since these patients are diagnosed faster due to the disease progression, while patients who opt for curative treatments undergo more tests to make a more accurate diagnosis, which lengthens waiting times [21].
For the diagnosis-to-treatment time, nine studies reported improved survival when the waiting time was shorter, three studies found no association between waiting time and survival or mortality, and nine studies reported improved survival when the waiting time was longer; in these studies the results obtained were justified by indicating that patients in more advanced stages, or who are older or with worse health are referred and treated more quickly than those in earlier stages, whose diagnosis may require more tests that delay the time to treatment, and in whom, despite being treated more quickly, due to the disease severity, the poor prognosis is not altered. In addition, the studies clarified that, despite these results, the timely treatment of patients with earlystage SCLC should be emphasized to prevent a worsening in staging, which has a large impact on survival [18, 22].

\section{Discussion}

We analyzed 38 articles on waiting times for the diagnosis and treatment of lung cancer published between 2010 and 2020 which related them to the prognosis. The studies selected were widely heterogeneous in terms of the design, the patient populations included, the structure of the health systems, the definition of the waiting time intervals evaluated, and the summary statistics used in the analysis of the results, which limits possible between-study comparisons. 
In similar studies, Olsson 2019 [6] reported a range of medians for the diagnosis to treatment time of 12.5-52 days, and from primary care visit to specialist visit time of 1-12 days; Jacobsen et al. [1] found a median range of 6-45 days and 1-17 days, respectively, for the same time intervals. In our review, medians of 6-121 days were found for the diagnosis to treatment time and 4-19.5 days for the primary care visit to specialist visit time, suggesting that waiting times have not improved and efforts should be made to reach the recommended standard times of a median of 15 days between diagnosis and treatment and 7 days between the primary care visit and the specialist visit [7].

We found that $35 \%$ of the time intervals studied showed no relationship between mean or median waiting times and the disease prognosis. Paradoxically, in the rest of the times studied, $37.5 \%$ found a better prognosis with longer waiting times and $27.5 \%$ a better prognosis with shorter waiting times. Jacobsen et al. [1] and Olsson [6] also obtained disparate results in terms of the proportion of articles that related better patient prognosis with longer times, shorter times, or that the prognosis was not affected by the waiting times, although in these reviews the results were not related to the specific waiting times, but a general evaluation of the relationship was made.

Although the results show that a high proportion of studies associated prolonged waiting times with a better prognosis, all of them justify this association, arguing for the importance of early care and detection in more serious patients. This suggests that to achieve a good management and prognosis of lung cancer these waiting times must be reduced. Most articles which associated shorter waiting times with a worse prognosis justified this relationship by stating that patients in more advanced stages, or who were older or had comorbidities, are referred and treated more quickly than those who are in earlier stages; in these more advanced patients, despite being treated more quickly, the poor prognosis did not change, resulting in shorter survival times. The diagnosis of patients in early stages may require more testing or evaluation by hospital committees, which delays diagnostic and treatment times, but may improve the prognosis because treatment is more targeted and individualized. In addition, many patients will receive surgical treatment, and the time spent on the waiting list until surgery can help prolong these intervals.

Special attention should be paid to the psychological stress to which patients are subjected throughout the process from diagnosis to treatment. As shown by Labbe et al. and Kasymjanova et al. [28, 32], shorter waiting times have positive repercussions in terms of anxiety, mental health, quality of life and patient satisfaction, and lead to lower treatment costs.
The global situation, in which COVID-19 has impacted on cancer waiting times in general, and lung cancer in particular, should be considered. Gheorghe et al. [38], modeled the potentially avoidable deaths due to delays in cancer diagnosis in England in response to the pandemic and estimated the economic and quality of life lost. Nearly 3620 deaths due to breast, bowel, lung, and esophageal cancer could have been avoided in the next 5 years, representing a loss of 32,700 QALYs and $€ 120.83$ million in productivity and, specifically in lung cancer, 10,900 QALYs and $€ 4.45$ million, compared with the 21,450 QALYs and $€ 88.96$ million lost due to deaths caused by COVID-19. Therefore, good coordination and early action in the management of lung cancer patients is essential to alleviate the delays and consequences derived from COVID-19.

One limitation of our study is the variation in the countries of the studies selected and the differences in health systems, which has a direct impact on waiting times and can cause confusion, as does the differing measures of waiting times, since each article defines these differently, which impacts on the comparability of the results and the complexity of the interpretation. However, we used PubMed and Embase to extract most available studies on the objective, thus providing an overview of the waiting times lung cancer patients are subject to and a detailed analysis of these times with the prognosis.

Generally, the waiting times usually include biases. The times are not accelerated if the patient is in the earlier disease stages, but they are in the advanced stages, due to the high mortality in this type of cancer, which results in contradictory results. As indicated by Adizie et al. [39], there are also more factors that skew waiting times, such as physician's workloads and the organization of the treating center, which negatively affect the survival of lung cancer patients, the type of curative treatment administered and reductions in waiting times. Further prospective evidence is required to enable studies designed to provide more data on the relationship between waiting times and lung cancer prognosis.

In conclusion, patients value timely and effective care, and it is important to improve the diagnostic and therapeutic waiting times to which lung cancer patients are subjected, especially because these times influence the prognosis, with the aim of increasing the cure rate or, where appropriate, improving the quality of life and prolonging survival.

\section{Appendix A}

See Tables 2 and 3. 


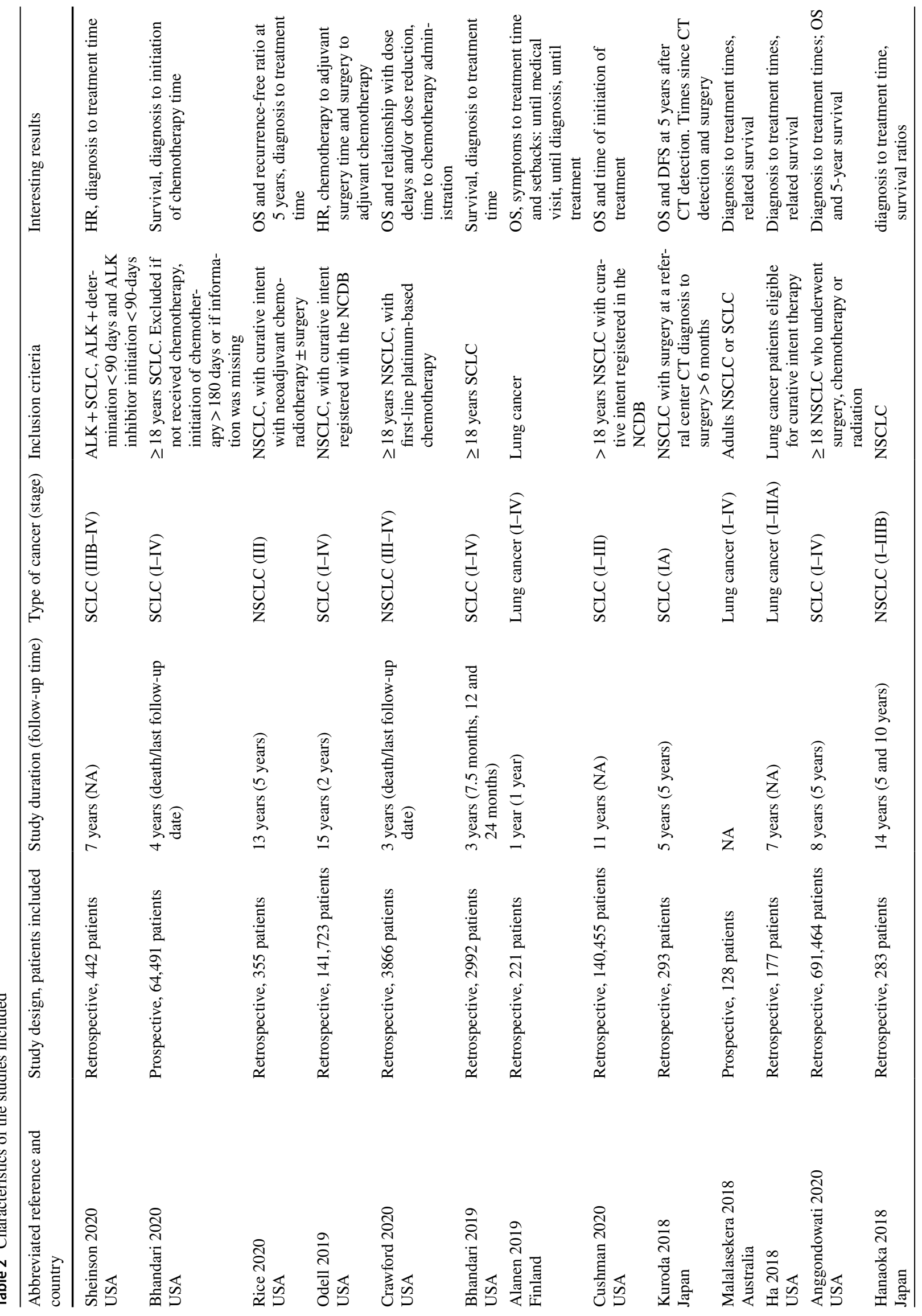




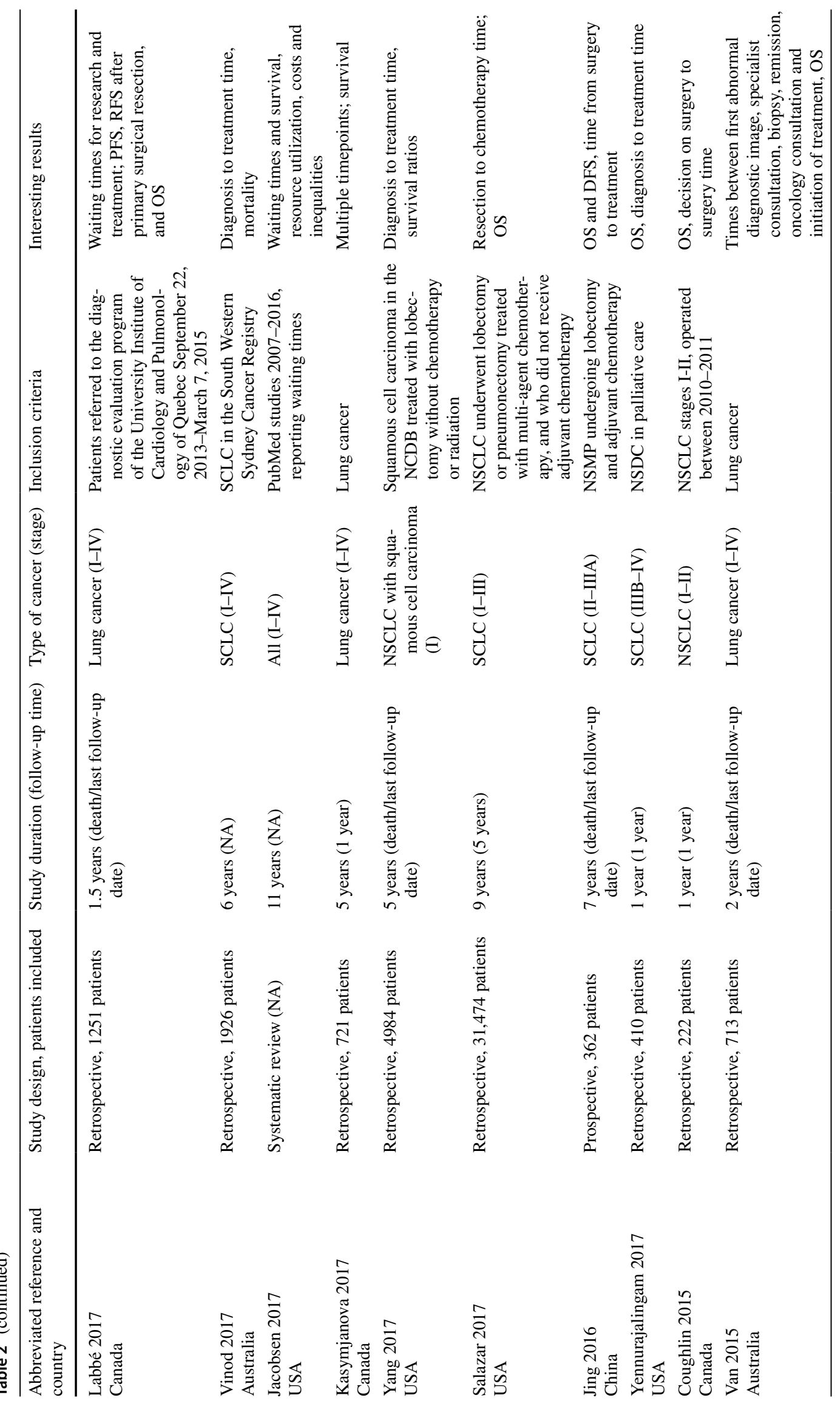




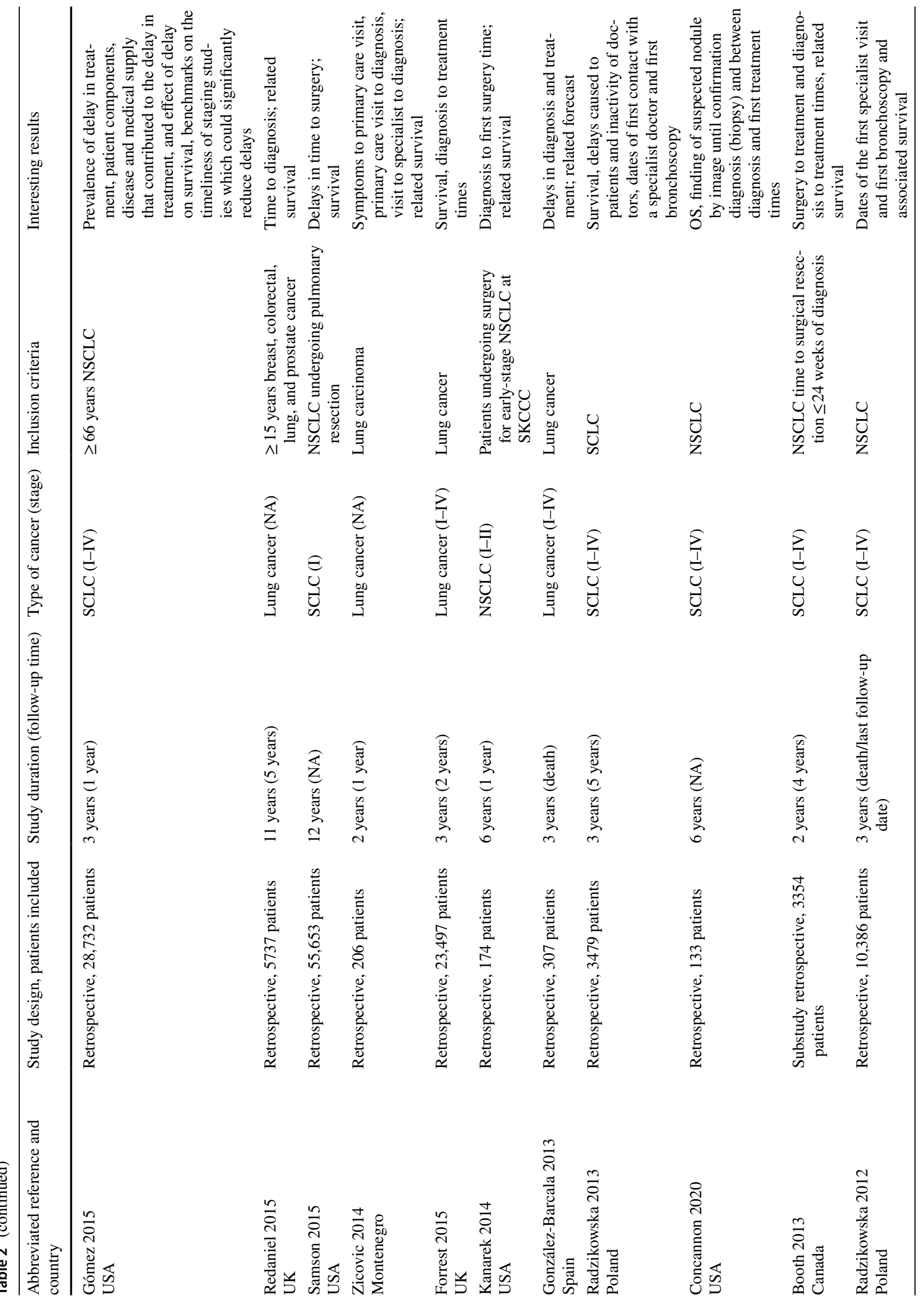



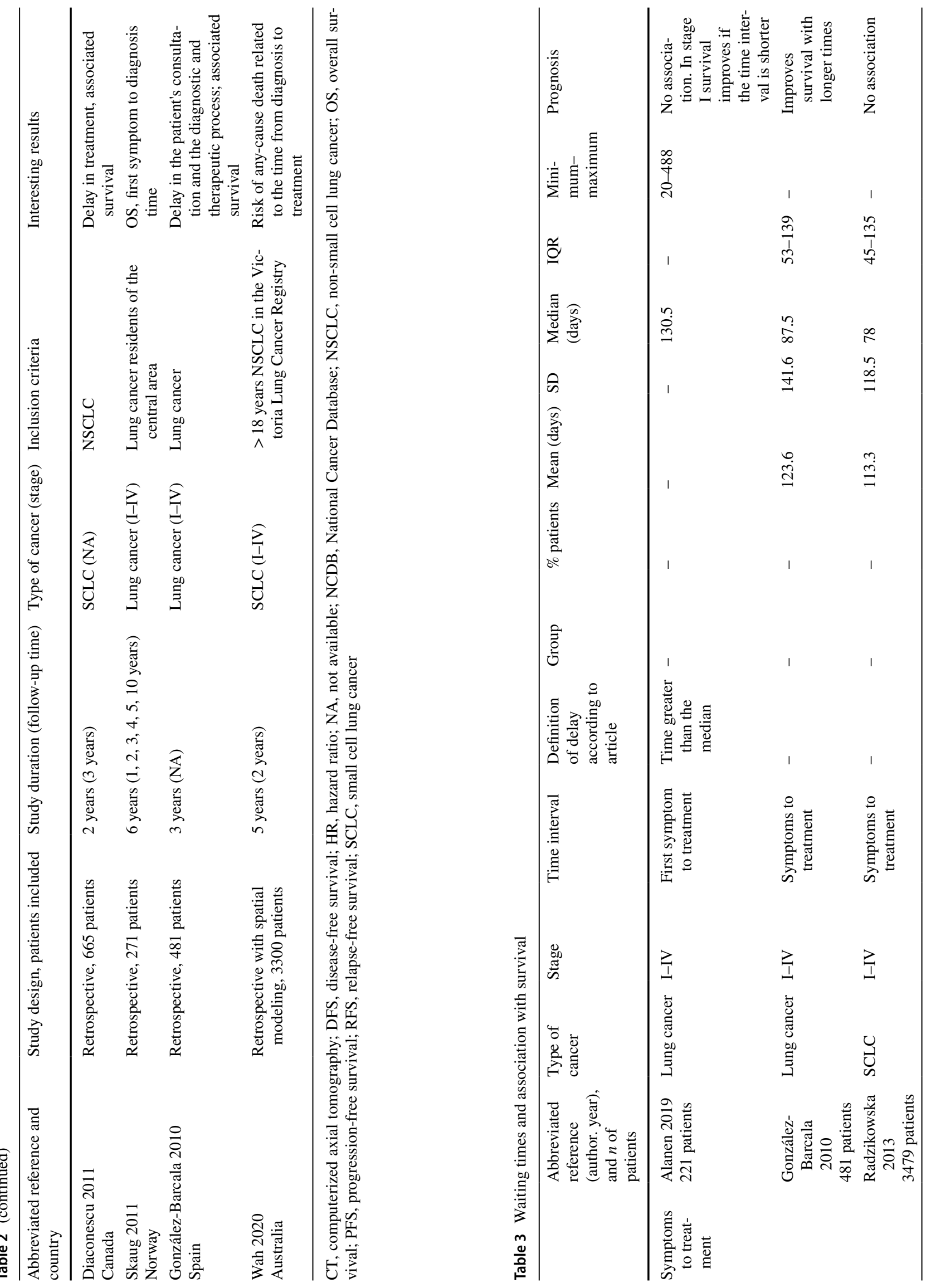


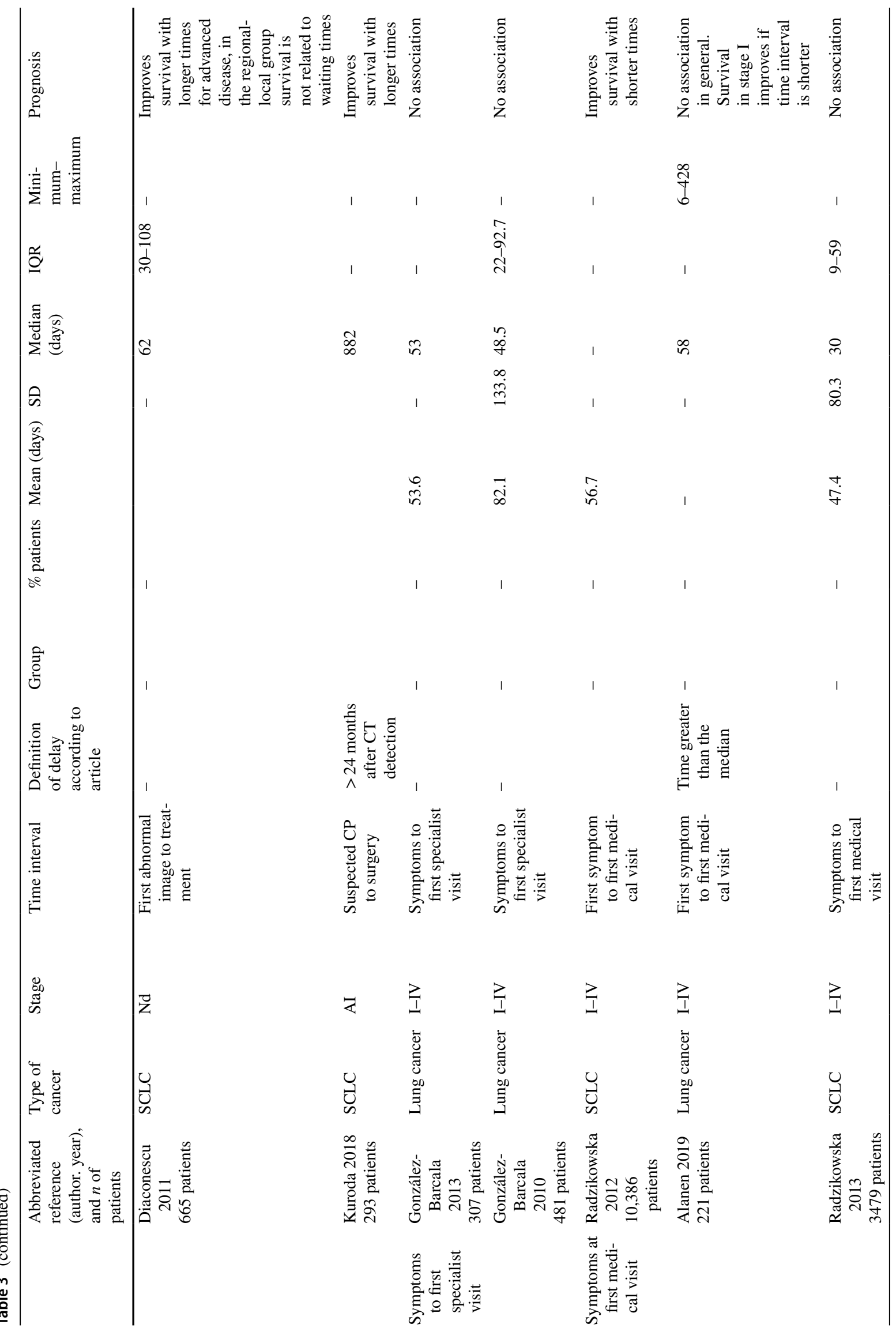




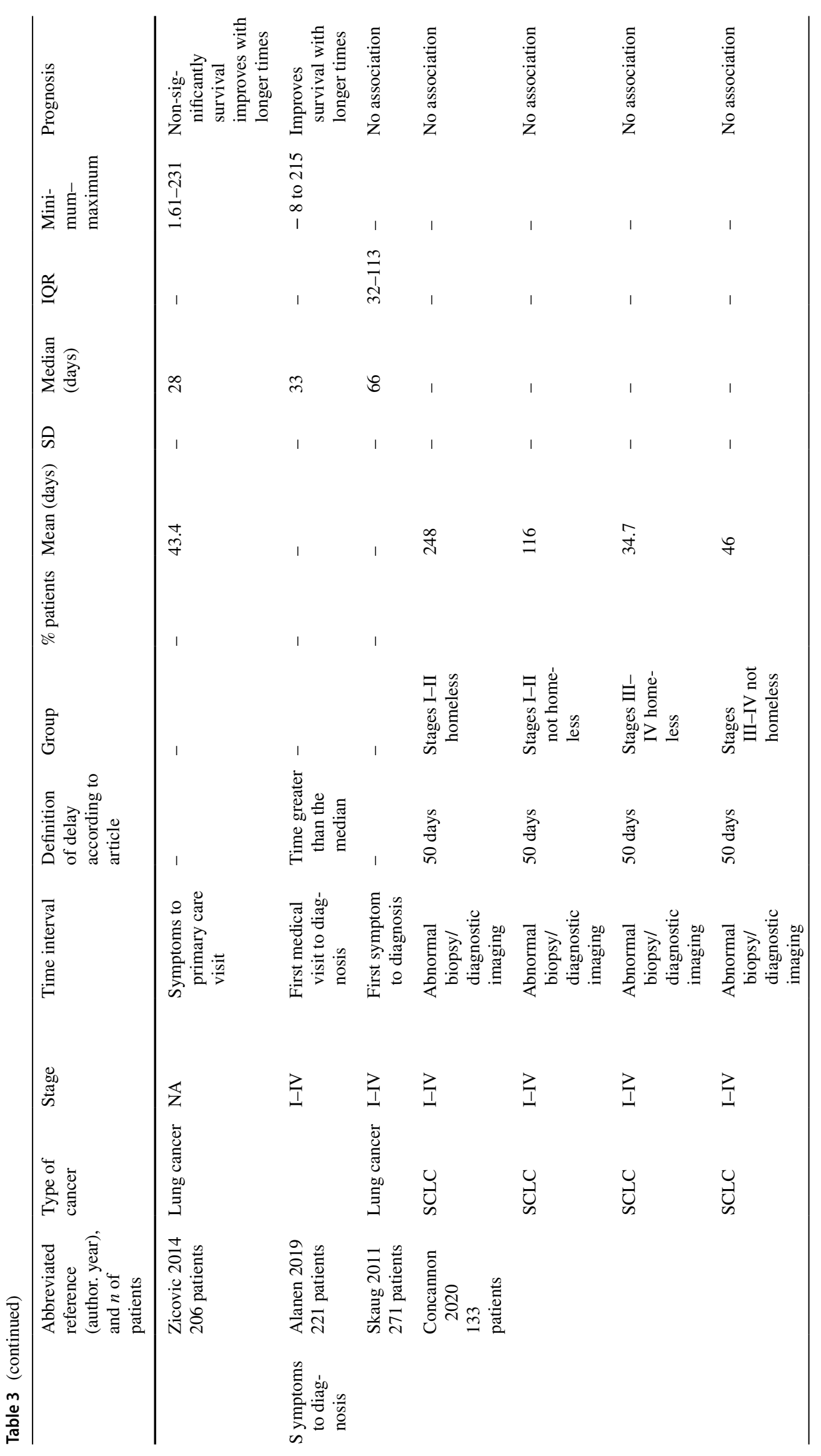




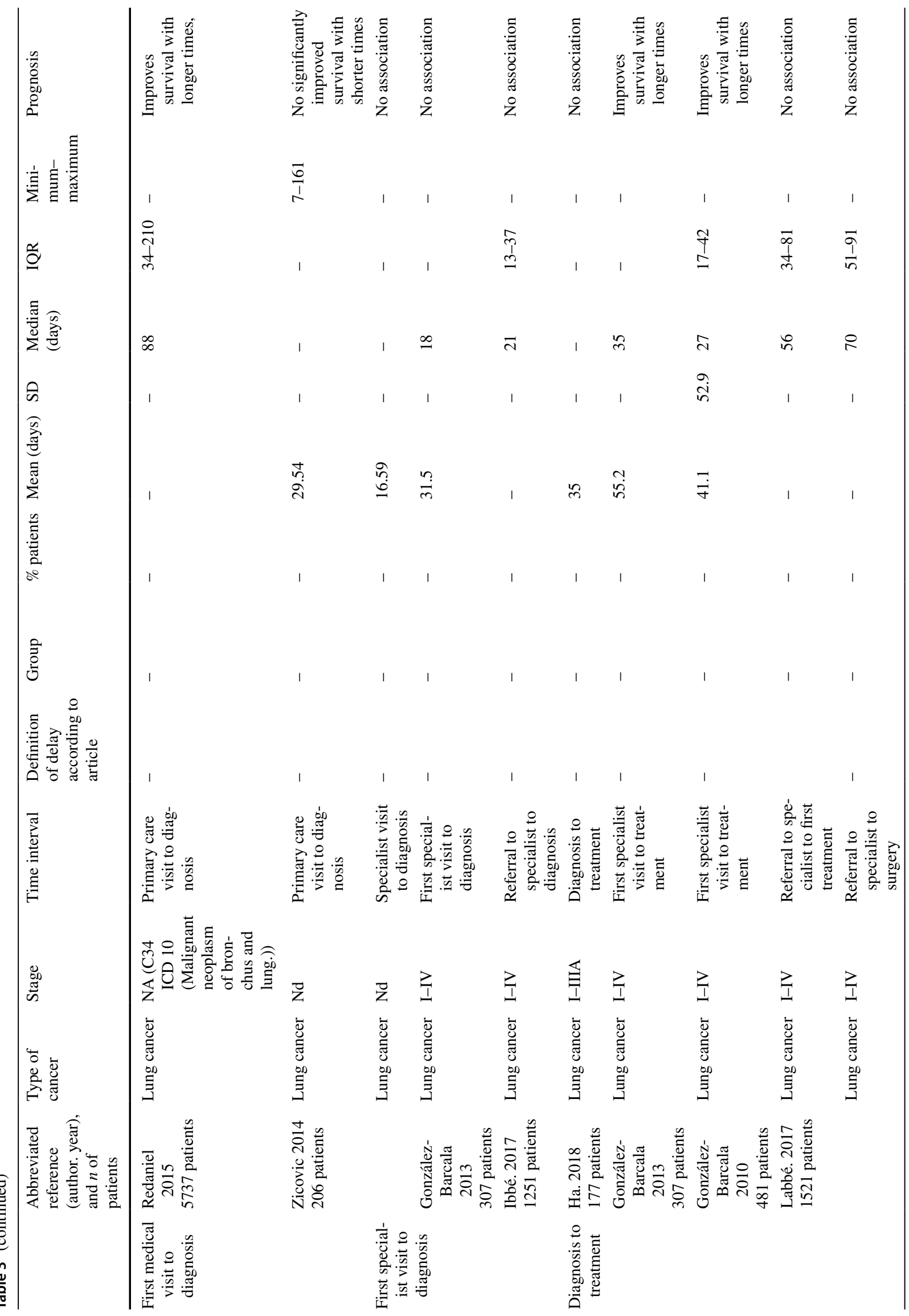




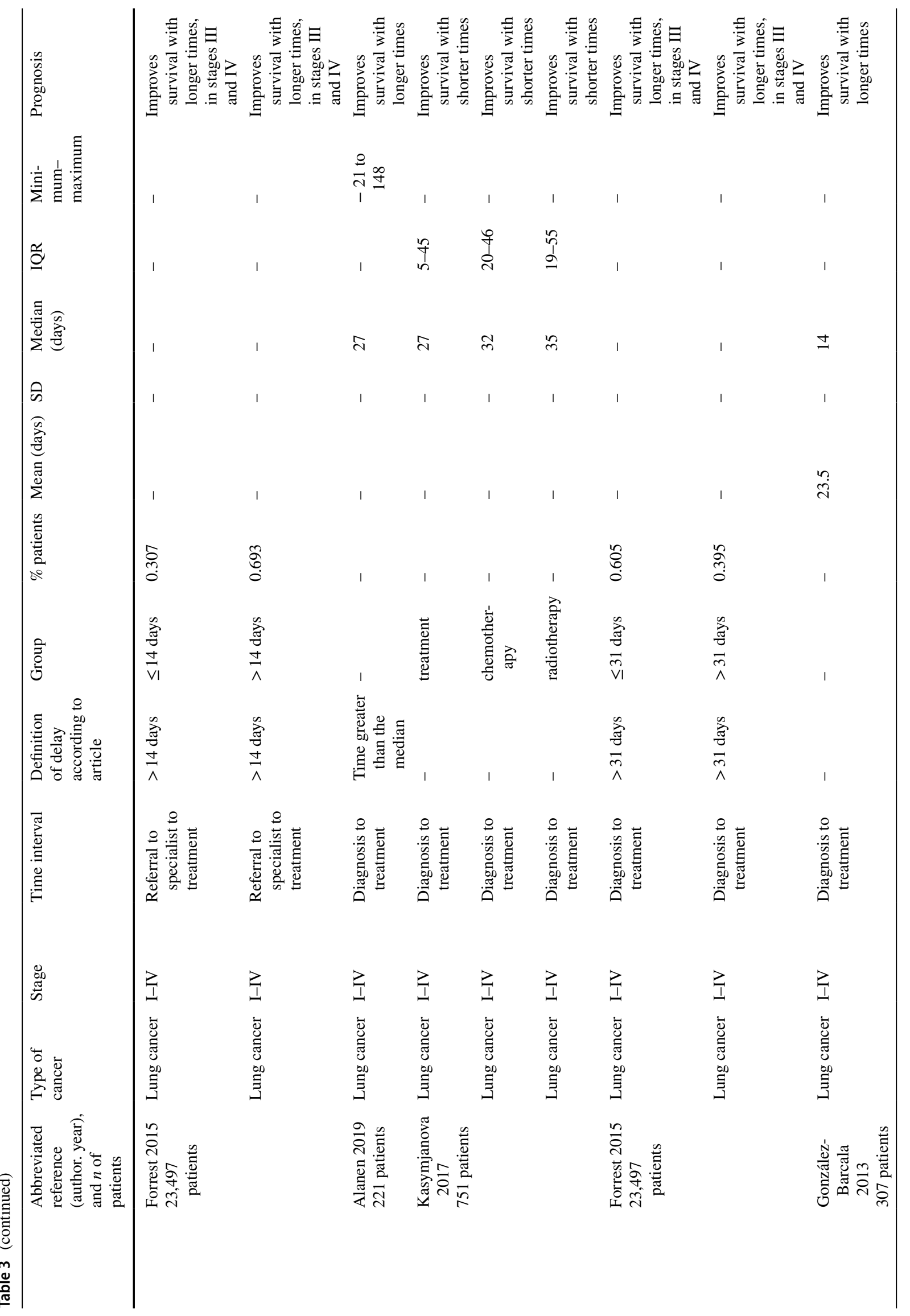




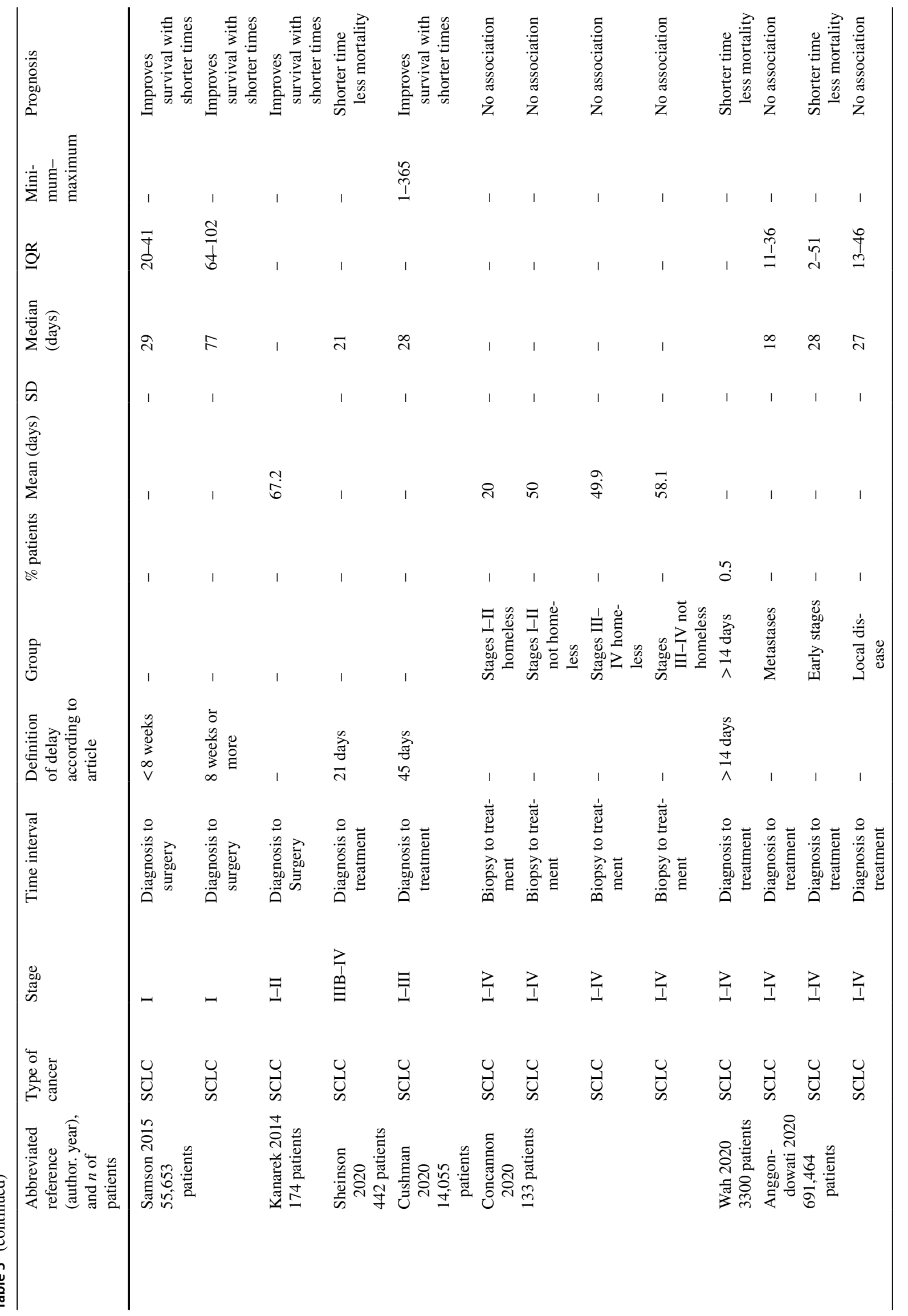




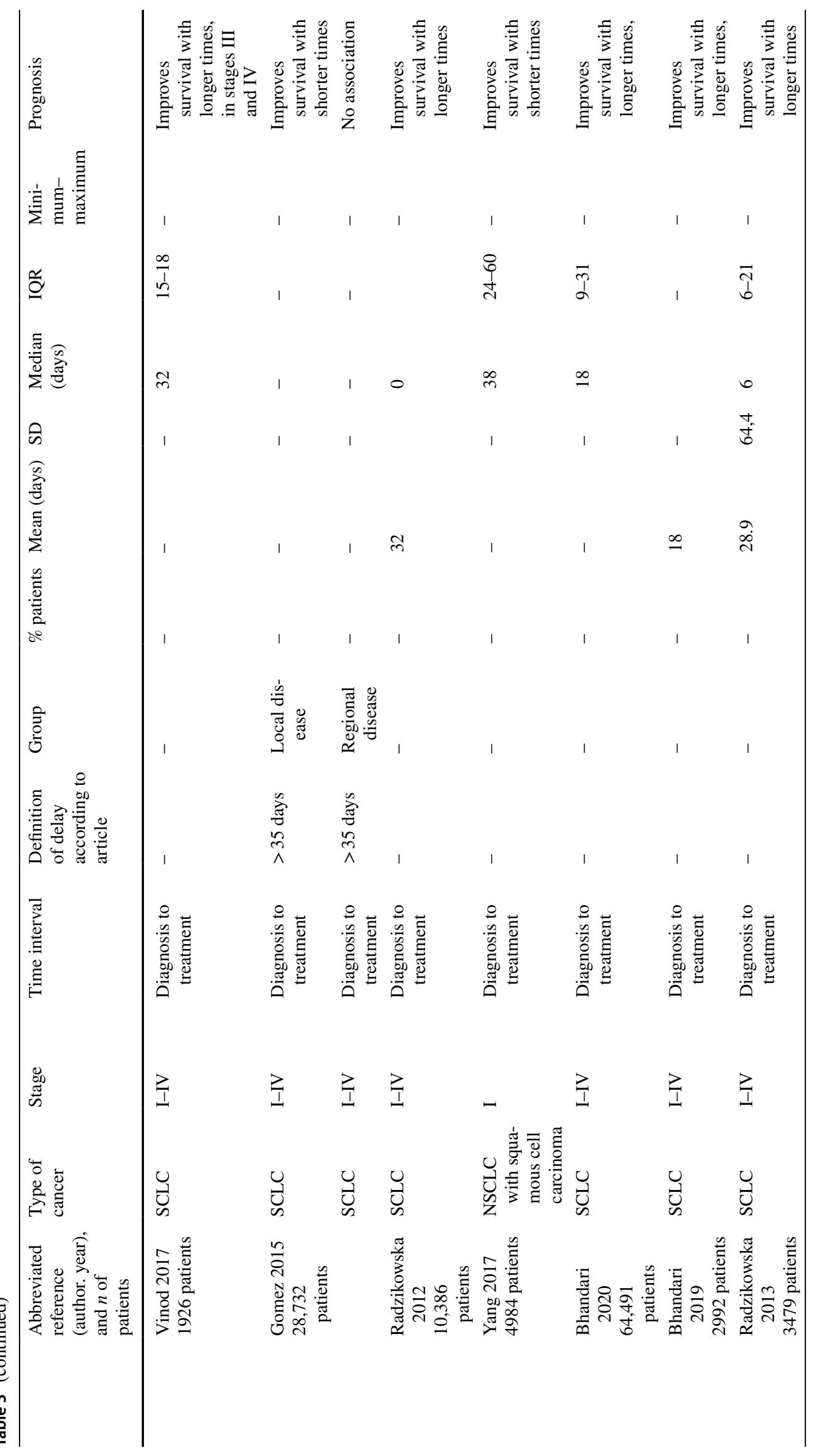




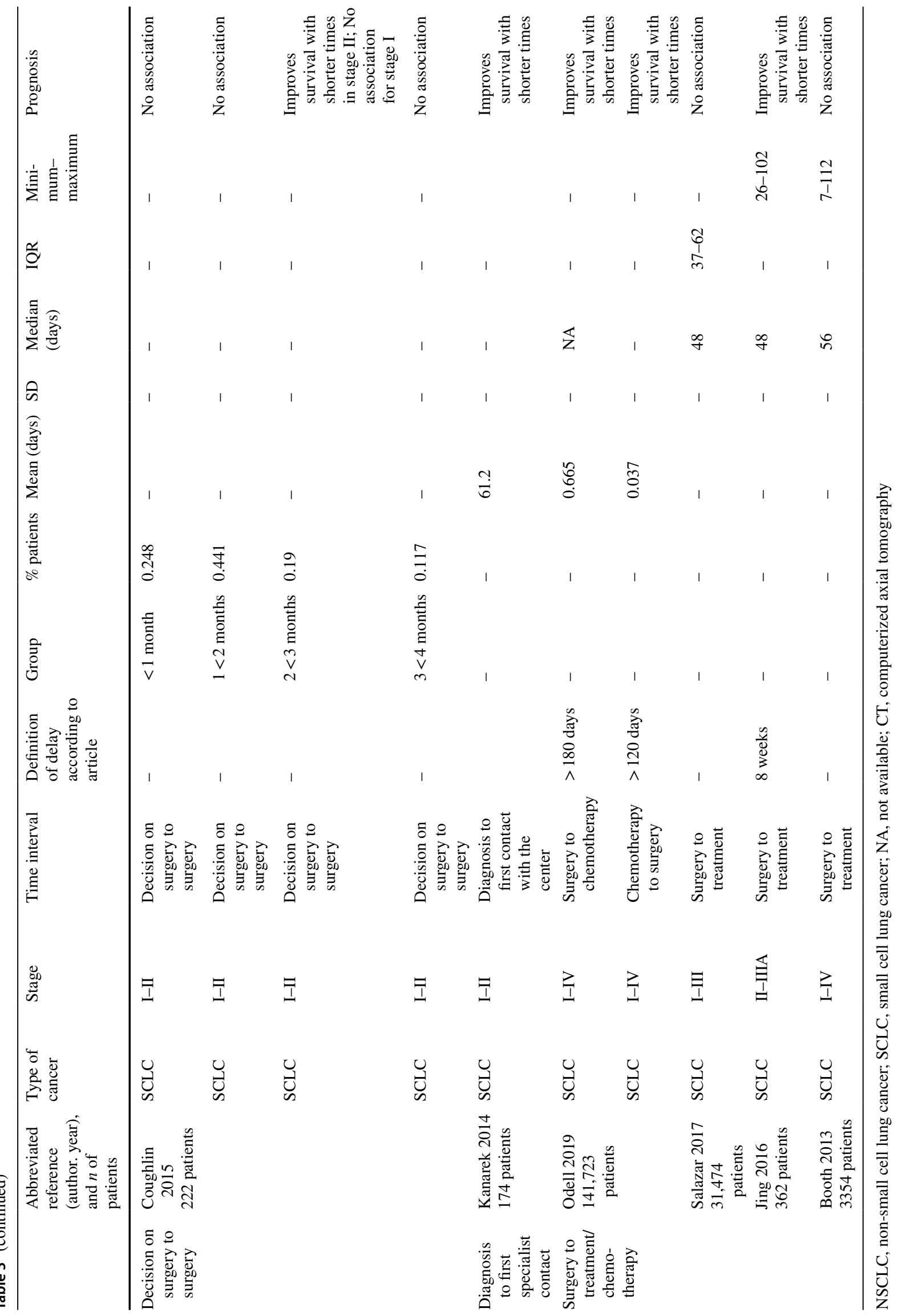


Acknowledgements The authors acknowledge Oblikue Consulting S.L for the support given to write this manuscript.

Author contributions MG, EFM, JAFV, ANM, and ASH contributed to the conceptualization, validation, analysis, data curation, writingoriginal draft preparation, writing-review and editing. All authors have read and agreed to the published version of the manuscript.

Funding This research was funded from consultancy fees received from AstraZeneca Farmacéutica España S.A.

Data availability statement The datasets generated and/or analyzed during the current study are available from the corresponding author upon reasonable request.

\section{Declarations}

Conflict of interest The authors declare no conflict of interest. The founding sponsors had no role in the design of the study; in the collection, analyses, or interpretation of data; in the writing of the manuscript, and in the decision to publish the results.

Ethical approval and Informed consent This study was a SLR based on a published studies consequently this research did not envolve humans and/or animals participants.

Open Access This article is licensed under a Creative Commons Attribution 4.0 International License, which permits use, sharing, adaptation, distribution and reproduction in any medium or format, as long as you give appropriate credit to the original author(s) and the source, provide a link to the Creative Commons licence, and indicate if changes were made. The images or other third party material in this article are included in the article's Creative Commons licence, unless indicated otherwise in a credit line to the material. If material is not included in the article's Creative Commons licence and your intended use is not permitted by statutory regulation or exceeds the permitted use, you will need to obtain permission directly from the copyright holder. To view a copy of this licence, visit http://creativecommons.org/licenses/by/4.0/.

\section{References}

1. Jacobsen MM, Silverstein SC, Quinn M, Waterston LB, Thomas CA, Benneyan JC, et al. Timeliness of access to lung cancer diagnosis and treatment: a scoping literature review. Lung Cancer. 2017;112:156-64.

2. Vinas F, Ben Hassen I, Jabot L, Monnet I, Chouaid C. Delays for diagnosis and treatment of lung cancers: a systematic review. Clin Respir J. 2016;10:267-71.

3. Sociedad Española de Oncología Médica (SEOM). Las cifras del cáncer en España. 2021.

4. American Cancer Society. Tasas de supervivencia del cáncer de pulmón [Internet]. 2021. https://www.cancer.org/es/cancer/cancer-de-pulmon/deteccion-diagnostico-clasificacion-por-etapas/ tasas-de-supervivencia.html. Cited 27 May 2021.

5. GLOBOCAN 2020 [Internet]. https://gco.iarc.fr/today/onlineanalysis-table $\mathrm{v}=2020 \&$ mode $=$ cancer $\&$ mode $\_$population $=$conti nents $\&$ population $=900 \&$ populations $=900 \& \mathrm{key}=$ asr $\& \mathrm{sex}=0 \&$ cancer $=39 \&$ type $=1 \&$ statistic $=5 \&$ prevalence $=0 \&$ population group $=0 \&$ ages_group $\% 5 \mathrm{~B} \% 5 \mathrm{D}=0 \&$ ages_group $\% 5 \mathrm{~B} \% 5 \mathrm{D}=17 \&$ group_cancer $=1 \&$ include_nmsc $=1 \&$ include_nmsc_other $=1$. Cited 4 May 2021.
6. Olsson JK, Schultz EM, Gould MK. Timeliness of care in patients with lung cancer: a systematic review. Thorax. 2009;64:749-56.

7. Ministerio de Sanidad. Estrategia en Cáncer del Sistema Nacional de Salud. 2021.

8. Malalasekera A, Nahm S, Blinman PL, Kao SC, Dhillon HM, Vardy JL. How long is too long? A scoping review of health system delays in lung cancer. Eur Respir Rev. 2018;27:180045.

9. Nasim F, Sabath BF, Eapen GA. Lung cancer. Medical clinics of North America. Philadelphia: W.B. Saunders; 2019. p. 463-73.

10. Kuroda H, Sugita Y, Ohya Y, Yoshida T, Arimura T, Sakakura N, et al. Importance of avoiding surgery delays after initial discovery of suspected non-small-cell lung cancer in clinical stage IA patients. Cancer Manag Res. 2018;11:107-15.

11. Concannon KF, Thayer JH, Wu QV, Jenkins IC, Baik CS, Linden HM. Outcomes among homeless patients with non-smallcell lung cancer: a county hospital experience. JCO Oncol Pract. 2020;16:e1004-14.

12. Zivkovic D. Effect of delays on survival in patients with lung carcinoma in Montenegro-PubMed. Acta Clin Croat. 2014;53(4):390-8.

13. Redaniel MT, Martin RM, Ridd MJ, Wade J, Jeffreys M. Diagnostic intervals and its association with breast, prostate, lung and colorectal cancer survival in England: historical cohort study using the clinical practice research datalink. Metze K, editor. PLoS ONE. 2015;10:e0126608.

14. Forrest LF, Adams J, Rubin G, White M. The role of receipt and timeliness of treatment in socioeconomic inequalities in lung cancer survival: population-based, data-linkage study. Thorax. 2015;70:138-45.

15. Samson P, Patel A, Garrett T, Crabtree T, Kreisel D, Krupnick AS, et al. Effects of delayed surgical resection on short-term and long-term outcomes in clinical stage I non-small cell lung cancer. Ann Thorac Surg. 2015;99:1906-13.

16. Rice SR, Vyfhuis MAL, Scilla KA, Burrows WM, Bhooshan $\mathrm{N}$, Suntharalingam $\mathrm{M}$, et al. Insurance status is an independent predictor of overall survival in patients with stage III non-smallcell lung cancer treated with curative intent. Clin Lung Cancer. 2020;21:e130-41.

17. Anggondowati T, Ganti AK, Islam KMM. Impact of time-to-treatment on overall survival of non-small cell lung cancer patientsan analysis of the national cancer database. Transl Lung Cancer Res. 2020;9:1202-11.

18. Bhandari S, Pham D, Pinkston C, Oechsli M, Kloecker G. Timing of treatment in small-cell lung cancer. Med Oncol. 2019;36:47.

19. Kanarek NF, Hooker CM, Mathieu L, Tsai H-L, Rudin CM, Herman JG, et al. Survival after community diagnosis of early-stage non-small cell lung cancer. Am J Med. 2014;127:443-9.

20. Odell DD, Feinglass J, Engelhardt K, Papastefan S, Meyerson SL, Bharat A, et al. Evaluation of adherence to the commission on cancer lung cancer quality measures. J Thorac Cardiovasc Surg. 2019;157:1219-35.

21. Alanen V, Koivunen JP. Association of diagnostic delays to survival in lung cancer: single center experience. Acta Oncol. 2019;58:1056-61.

22. Radzikowska E, Roszkowski-Sliz K, Chabowski M, Glaz P. Influence of delays in diagnosis and treatment on survival in small cell lung cancer patients. 2013:355-62.

23. González-Barcala FJ, García-Prim JM, Álvarez-Dobaño JM, Moldes-Rodríguez M, García-Sanz MT, Pose-Reino A, et al. Effect of delays on survival in patients with lung cancer. Clin Transl Oncol. 2010;12:836-42.

24. Diaconescu R, Lafond C, Whittom R. Treatment delays in nonsmall cell lung cancer and their prognostic implications. J Thorac Oncol. 2011;6:1254-9. 
25. Gonzalez-Barcala FJ, Falagan JA, Garcia-Prim JM, Valdes L, Carreira JM, Puga A, et al. Timeliness of care and prognosis in patients with lung cancer. Ir J Med Sci (1971-). 2014;183:383-90.

26. Radzikowska E, LastNameRoszkowski-Śliż K, Gła P. The impact of timeliness of care on survival in non-small cell lung cancer patients-PubMed. Pneumonol Alergol Pol. 2012;80(5):422-9.

27. Skaug K, Eide GE, Gulsvik A. Predictors of long-term survival of lung cancer patients in a Norwegian community. Clin Respir J. 2011;5:50-8.

28. Labbé C, Anderson M, Simard S, Tremblay L, Laberge F, Vaillancourt R, et al. Wait times for diagnosis and treatment of lung cancer: a single-centre experience. Curr Oncol. 2017;24:367-73.

29. Ha D, Ries AL, Montgrain P, Vaida F, Sheinkman S, Fuster MM. Time to treatment and survival in veterans with lung cancer eligible for curative intent therapy. Respir Med. 2018;141:172-9.

30. Vinod SK, Chandra A, Berthelsen A, Descallar J. Does timeliness of care in non-small cell lung cancer impact on survival? Lung Cancer. 2017;112:16-24.

31. Bhandari S, Kumar R, Pham D, Gaskins J, Kloecker G. Treatment timing in small cell lung cancer, a national cancer database analysis. Am J Clin Oncol. 2020;43:362-5.

32. Kasymjanova G, Small D, Cohen V, Jagoe RT, Batist G, Sateren W, et al. Lung cancer care trajectory at a Canadian centre: an evaluation of how wait times affect clinical outcomes. Curr Oncol. 2017;24:302-9.

33. Sheinson D, Wong WB, Wu N, Mansfield AS. Impact of delaying initiation of anaplastic lymphoma kinase inhibitor treatment on survival in patients with advanced non-small-cell lung cancer. Lung Cancer. 2020;143:86-92.
34. Cushman TR, Jones B, Akhavan D, Rusthoven CG, Verma V, Salgia $\mathrm{R}$, et al. The effects of time to treatment initiation for patients with non-small-cell lung cancer in the United States. Clin Lung Cancer. 2021;22:e84-97.

35. Wah W, Stirling RG, Ahern S, Earnest A. Influence of timeliness and receipt of first treatment on geographic variation in non-small cell lung cancer mortality. Int J Cancer. 2021;148:1828-38.

36. Gomez DR, Liao K-P, Swisher SG, Blumenschein GR, Erasmus JJ, Buchholz TA, et al. Time to treatment as a quality metric in lung cancer: staging studies, time to treatment, and patient survival. Radiother Oncol. 2015;115:257-63.

37. Yang C-FJ, Wang H, Kumar A, Wang X, Hartwig MG, Damico TA, et al. Impact of timing of lobectomy on survival for clinical stage IA lung squamous cell carcinoma. Chest. 2017;152:1239-50.

38. Gheorghe A, Maringe C, Spice J, Purushotham A, Chalkidou $\mathrm{K}$, Rachet $\mathrm{B}$, et al. Economic impact of avoidable cancer deaths caused by diagnostic delay during the COVID-19 pandemic: a national population-based modelling study in England, UK. Eur J Cancer. 2021.

39. Adizie JB, Khakwani A, Beckett P, Hubbard R, Navani N, Harden $\mathrm{SV}$, et al. Impact of organisation and specialist service delivery on lung cancer outcomes. Thorax. 2019;74:546-50.

Publisher's Note Springer Nature remains neutral with regard to jurisdictional claims in published maps and institutional affiliations. 